\title{
¿Qué tan rezagada está la Costa Caribe en el siglo XXI?
}

\section{How straggler is the Caribbean Coast in the 21st century?}

\author{
Salomón Kalmanovitz \\ Doctorado honoris causa en Economía, Universidad del Norte \\ Profesor Emérito de la Universidad de Bogotá Jorge Tadeo Lozano, Colombia \\ https://orcid.org/0000-0001-5682-4613 \\ salomon.kalmanovitz@utadeo.edu.co
}

Fecha de recepción: 31 de mayo del 2019 Fecha de aceptación: 15 de junio del 2019

Disponible en línea: 1 de julio del 2019

Sugerencia de citación: Kalmanovitz, S. (2019). ¿Qué tan rezagada está la Costa Caribe en el siglo XXI? tiempo\&economía, 6(2), 81-101 doi: http://dx.doi.org/10.21789/24222704.1503

\section{RESUMEN}

Hace 20 años Adolfo Meisel publicó un ensayo sobre las condiciones que propiciaron el atraso de la Costa Caribe frente a otras regiones del país. La política proteccionista fue contraproducente en aquellas que tenían alto potencial para exportar materias primas, pues indujo una revaluación del peso; mientras que el contrabando competía contra la protegida industria barranquillera, sin lesionar a las de Medellín, Cali y Bogotá. La política de apertura benefició algo más a la Costa Caribe, pero suscitó nuevos problemas en el siglo XXI, como la enfermedad holandesa que contribuyó a la desindustrialización de Barranquilla pero no impidió el desarrollo petro-industrial de Cartagena ni el de Valledupar y Santa Marta. La región redujo sus desventajas, pero aún es pobre, con una fuerte desigualdad causada por la ancestral relación entre sus élites y la ciudadanía.

Palabras clave: desarrollo regional, desarrollo económico, Costa Caribe, política económica y fiscal, historia económica.

Códigos JEL: E62, R11 


\section{ABSTRACT}

Twenty years ago, Adolfo Meisel published an essay on the conditions that led to the backwardness of the Caribbean Coast compared to other regions of the country. The protectionist policy was counterproductive in those regions with high potential to export raw materials, because it induced a revaluation of the peso; while smuggling competed against the protected industry of Barranquilla, without injuring those of Medellin, Cali and Bogota. The policy of openness brought more benefits for the Caribbean Coast, but raised new problems in the $21 \mathrm{st}$ century, such as the Dutch disease that contributed to the deindustrialization of Barranquilla but did not prevent oil industry from being developed in Cartagena or in Valledupar and Santa Marta. The region reduced its disadvantages, but it is still poor, with a strong inequality caused by the ancestral relationship between its elites and citizens.

Keywords: regional development, economic development, Caribbean coast, economic and fiscal policy, economic history.

JEL Codes: E62, R11 


\section{Introducción}

El ensayo “Por qué perdió la Costa Caribe el siglo XX”?, de Adolfo Meisel, me causó una profunda impresión cuando lo leí por vez primera; pensé que era muy convincente, pues analizaba en profundidad los factores que habían incidido en el cambio de fortuna de la Costa Caribe, pero dejaba por fuera elementos de la estructura social y política de la región que se debían introducir para que el análisis fuera más comprehensivo. Hoy me pareció apropiado establecer un diálogo veinte años después de su publicación, pero, sobre todo, actualizando las estadísticas y tratando de comprender los grandes cambios ocasionados por la apertura económica y la gran ampliación exportadora del sector minero energético en el desarrollo regional. Me puse a la tarea a mano alzada, o sea, sin un análisis detallado de los cambios acaecidos, que habría demandado un enorme esfuerzo y un tiempo del que no contaba.

Colombia es un país escasamente desarrollado, incluso en el ámbito latinoamericano. Su ingreso por habitante es el $60 \%$ del de los países australes, el $80 \%$ del de México, nos acercamos al de Brasil, y superamos al de Perú en 2016 (Maddison, 2018). Las razones son varias, algunas compartidas por la región, que provienen de las instituciones sembradas por la colonización española y portuguesa; otras idiosincrásicas, que obedecen a su dotación y su ubicación geográfica, a su integración tardía a la globalización capitalista y, sobre todo, a su historia de inestabilidad política en el siglo XIX; y, además, a su tortuosa construcción del Estado durante el siglo siguiente. Lo que argumento a continuación es que el déficit de Estado nacional es una barrera para el desarrollo económico, y que la debilidad de gobiernos locales y regionales es también un obstáculo para la prosperidad de ciudades y regiones.

En el conjunto de las regiones colombianas, los departamentos caribeños no son los más pobres si se los compara con los de la Costa Pacífica, en particular con Chocó, Cauca y Nariño. En 2015, Bolívar presentó un ingreso por habitante del 9\%, superior al promedio y el de Atlántico fue igual, aunque en 1950 era uno de los más ricos del país (un 80\% superior al promedio); Cesar está un 5\% por encima, pero Magdalena, Córdoba, La Guajira y Sucre están bastante por debajo del resto. Los departamentos cafeteros también se han empobrecido considerablemente, mientras que Antioquia y Valle del Cauca se mantienen arriba, pero los departamentos de Santander (un 150\% más que el promedio, gracias en parte al petróleo) y Bogotá (93\%) son los más ricos, descontando a los nuevos productores de petróleo (Meta y Casanare) que generan muchas más rentas y utilidades que salarios y empleo. Igual sucede con las regiones productoras de carbón y níquel, en una magnitud similar a las que producen oro en forma industrial. Más adelante, examino las disparidades regionales con mayor detalle.

El desarrollo sostenido del país se basó en la caficultura, que jalonó la industria en Antioquia y los servicios y manufacturas de Bogotá, Cali y Barranquilla. La economía era bastante abierta, con un arancel promedio del $25 \%$ en la década de 1930, que se redujo después de 1945 gracias al auge de los precios del café. A partir de 1949, sin embargo, la segunda república conservadora inauguró una política de protección a la agricultura y a la industria que lesionó los intereses de los agricultores y ganaderos costeños que podían exportar, así como la industria barranquillera. El modelo de desarrollo protegido benefició en especial a los departamentos de Antioquia y Valle del Cauca y a Bogotá, que se comunicaban con el globo a través del puerto de Buenaventura, el cual terminó desplazando al de Barranquilla y demás 
puertos del mar Caribe con la apertura en firme del canal de Panamá en 1920, después del fin de la Primera Guerra Mundial. Ello explica el auge del triángulo Medellín-Cali-Bogotá, y el lento desarrollo de la Costa Caribe, que se ralentizó aún más desde la década de 1950. En la década de 1990 se abrió la economía y ello permitió que la región progresara relativamente, pero como su desarrollo centrado en las exportaciones minero-energéticas es de enclave, genera poco empleo, y sus consecuencias sobre la tasa de cambio y la competitividad de la industria y la agricultura resultaron negativas para ambos sectores y para los departamentos de la Costa Caribe, salvo para Cartagena, que contó con el fuerte desarrollo de la petroquímica y la química básica.

He ordenado el artículo para recalcar que Colombia no hizo un gran progreso en el siglo XX, y aunque parece haberle ido mejor en el siglo XXI, lo fue a costa de sectores transables como la industria y la agricultura. No es sorprendente que a ninguna región le haya ido especialmente bien, aunque Bogotá sigue siendo la capital de los privilegios. Quiero resaltar que uno de los grandes obstáculos al progreso económico nacional es la debilidad de Estado, tanto en el nivel central como en el de las regiones y municipios, aunque ha habido un progreso considerable en ambos niveles. Hago entonces un balance preliminar del avance de la Costa Caribe comparado con el de las otras regiones. Lo cierto es que la apertura terminó favoreciéndola más que el modelo protegido que criticó Meisel en su trabajo y que progresó más que a nivel nacional. Continúo con un breve comentario sobre los antecedentes históricos de la Costa Caribe y algunos indicadores del siglo XIX, luego actualizo los datos de Meisel a 2015 y muestro el fuerte surgimiento de Bolívar y Cesar, el ocaso del Atlántico y el estancamiento relativo de Magdalena, Córdoba, Sucre y La Guajira. Analizo el origen de las disparidades regionales y recuento las razones expuestas por García-García (2008) y Meisel (1999) para el atraso relativo de la economía costeña. Añado una sección sobre los factores propios que impidieron un desarrollo económico más profundo, como la estructura de tenencia de la tierra y la fuerte estratificación social -además de la baja tributación, que llevaron a que la región no invirtiera lo suficiente en educación y otros bienes públicos que lubricaran su desarrollo. Luego doy una mirada a vuelo de pájaro de la política, que tampoco ayudó durante buena parte del siglo XX, pero sorprendentemente observo un renacimiento de la vida municipal que convierte a la mayoría de las ciudades caribeñas en polos de desarrollo para la región.

\section{Antecedentes históricos}

La Costa Caribe fue colonizada tardíamente y de manera incompleta, con excepción de la provincia de Cartagena, en la que se situó uno de los tres grandes puertos del Imperio español. Santa Marta, Riohacha, Valledupar y la Sierra Nevada de Santa Marta fueron ocupadas parcialmente y se desarrollaron pobremente durante el siglo XIX. Los arhuacos y wayúus fueron catequizados por los capuchinos, con alcances limitados, y solo aprendieron español en el siglo XX, aunque no del todo. Cartagena era la provincia más rica de la Nueva Granada, puerto de entrada de esclavos y mercancías, de salida de oro y plata de Perú; recibía enormes recursos, el situado o transferencias para construir y mantener murallas, castillos y fuertes. La guerra de independencia la dejó arruinada y despoblada, y tuvo un lento desarrollo durante el siglo XIX. 
En la Costa Caribe hubo una lenta evolución de formas de organización precolombinas, que se transformaron sin un sometimiento riguroso a formas de trabajo organizadas. La Iglesia y sus órdenes más modernizantes -como los jesuitas- no tuvieron una presencia activa. Por tanto, se mantuvo una cultura pagana. Los esclavos se dedicaban, en parte, al servicio doméstico y a la construcción; no hubo un sólido sistema de haciendas, como en el Cauca y apareció un cimarronaje temprano. No obstante, el esclavismo dejó una profunda impronta en la sociedad bolivarense, con secuelas de segregación territorial y racial, que hoy se manifiestan en el limitado acceso de la población raizal a los derechos de propiedad. Según Cepeda y Meisel:

En la Costa Caribe se crearon haciendas esclavistas para producir azúcares y mieles que abastecían los mercados internos, así como haciendas ganaderas basadas en el trabajo de mestizos y mulatos. También existía una población rural excluida de la propiedad de la tierra y por fuera del control de las autoridades coloniales. Se trataba de una población de campesinos mestizos, en el sentido amplio del término, a los que se denominaba "arrochelados", que se resistían a caer bajo el dominio de los hacendados. (Cepeda \& Meisel, 2014, pp. 303-304)

La profunda segregación social fue más intensa en el sector rural que en las ciudades que se desarrollarían durante el siglo XX, de modo que las disparidades campo-ciudad fueron de las más agudas observadas en el país. Aunque es difícil afirmar que los españoles impusieron una cultura de trabajo en sus colonias, sí la trajeron sus colonos que pasaron a ser campesinos y artesanos en Antioquia y Santander, los cuales se asentaron en las tierras altas más salubres, donde tenían mayor acceso a la propiedad de la tierra o a formas híbridas y libres, como la aparcería, que en la Costa Caribe. En esta última región, como en otros territorios del virreinato, fueron comunes las grandes concesiones de la Corona y la entrega de baldíos durante la República, que eran colonizados por campesinos itinerantes, sin acceso permanente a la propiedad, quienes los devolvían sembradas con pastos (Fals Borda, 1984). La productividad del trabajo fue, en consecuencia, siempre baja.

Durante el siglo XIX los estados soberanos de la Costa Caribe fueron relativamente prósperos, de acuerdo con el recaudo tributario por habitante: Panamá era de lejos el líder, como eje del transporte, por su ferrocarril, entre el este y el oeste de los Estados Unidos, seguido de Bolívar y Antioquia en el segundo lugar; Magdalena ocupaba el tercer lugar como puerto y proveedor de sal de la región, pues la zona de La Guajira era parte de su territorio; Cundinamarca y Boyacá ocupaban el cuarto; Cauca, Tolima y Santander eran los más pobres. La prosperidad relativa de la Costa Caribe tenían que ver con el acceso al mercado amplio de las Antillas y a la prosperidad de Panamá y de Costa Rica, que exportaba café desde 1860, oportunidades que aprovechó Barranquilla cuando se conectó por ferrocarril con el corregimientos de Sabanilla y después con Puerto Colombia, que canalizó buena parte del comercio exterior del país después de 1870. Cartagena comenzó a recuperarse hacia la misma fecha. En Antioquia había una minería basada en mazamorreros independientes y campesinos libres que ya constituían un mercado interno creciente e inducían el desarrollo de habilidades industriales. Allí se estaba conformando una economía muy dinámica que le permitía obtener tributos similares a los del estado soberano de Bolívar y financiar un sistema educativo relativamente amplio. Cauca había perdido el lugar de privilegio que disfrutaba desde la Colonia, al colapsar sin remedio su minería basada en el esclavismo, y Tolima fue siempre una región poco dotada, aunque en el norte avanzaba la colonización antioqueña. En fin, el aislamiento de las regiones 
más apartadas de los circuitos globales de comercio determinó en buena medida su desarroIlo económico durante el largo siglo XIX colombiano (tabla 1).

Tabla 1. Recaudo por habitante en 1870, pesos corrientes

\begin{tabular}{cc}
\hline Departamento & Recaudo por habitante \\
Bntioquia & 0,95 \\
Bolívar & 0,95 \\
Caucá & 0,70 \\
Cundinamarca & 0,48 \\
Panamá & 0,82 \\
Santander & 1,40 \\
Tolima & 0,43 \\
\hline
\end{tabular}

Fuente: Kalmanovitz y López (2019, p. 46).

La inserción de Colombia en la economía mundial comenzó a finales del siglo XIX, pero, sobre todo, después de 1910, cuando la producción cafetera entró de lleno en tierras de colonización antioqueña. Se comenzó a generar un excedente económico nunca antes logrado que trastocó profundamente las relaciones sociales, la política dejó de ser dogmática para tornarse desarrollista, se intensificó el proceso de urbanización, se construyó infraestructura de transporte, se fundó un banco central independiente y se crearon las condiciones para la industrialización del país.

\section{Las disparidades regionales en los siglos XX y XXI}

En la primera mitad del siglo XX, el café se convirtió en el producto estrella y los departamentos que lo producían pasaron a ser los más ricos del país. El canal de Panamá entró en plena operación en la década de 1920; pero desde 1915 Cali estaba conectada con Buenaventura, que se convertiría en el principal puerto colombiano, por el que salían las exportaciones cafeteras y entraban los insumos para las industrias de Medellín, Cali y Bogotá, que Meisel (1999) identificó como el triángulo de oro. Barranquilla empezó a perder su preeminencia como puerto, aunque su dinámica industrial se mantuvo hasta la década de 1950. Su riqueza era comercial e industrial, alimentada por inmigrantes sirio-libaneses, italianos, alemanes y judíos; existía un ambiente cosmopolita y abierto que alentaba el desarrollo de los negocios (tabla 2). 
Tabla 2. PIB per cápita departamental dividido por el promedio nacional

\begin{tabular}{|c|c|c|c|c|}
\hline & 1950 & 2000 & 2015 & $\begin{array}{c}\text { Diferencia entre } 2015 \\
\text { y } 1950\end{array}$ \\
\hline Antioquia & 1,18 & 1,19 & 1,27 & 0,09 \\
\hline Atlántico & 1,79 & 0,97 & 0,99 & $-0,80$ \\
\hline Bogotá & 2,41 & 1,92 & 1,93 & $-0,48$ \\
\hline Bolívar & 1,00 & 0,86 & 1,09 & 0,09 \\
\hline Boyacá & 0,57 & 1,01 & 1,37 & 0,80 \\
\hline Caldas & 1,29 & 0,52 & 0,58 & $-0,71$ \\
\hline Casanare & & 5,62 & 2,68 & \\
\hline Cauca & 0,93 & 0,51 & 0,75 & $-0,18$ \\
\hline Cesar & 0,96 & 0,74 & 1,04 & 0,08 \\
\hline Chocó & 0,24 & 0,36 & 0,49 & 0,25 \\
\hline Córdoba & 0,57 & 0,67 & 0,60 & 0,03 \\
\hline Cundinamarca & 0,65 & 1,16 & 1,16 & 0,51 \\
\hline Huila & 0,6 & 0,91 & 0,94 & 0,34 \\
\hline La Guajira & 0,42 & 0,79 & 0,63 & 0,21 \\
\hline Magdalena & 0,96 & 0,54 & 0,61 & $-0,35$ \\
\hline Meta & 1,45 & 1,27 & 2,38 & 0,93 \\
\hline Nariño & 0,46 & 0,48 & 0,55 & 0,09 \\
\hline Norte Santander & 0,91 & 0,48 & 0,55 & $-0,36$ \\
\hline Quindío & 1,23 & 0,67 & 0,73 & $-0,50$ \\
\hline Risaralda & 1,37 & 0,84 & 0,92 & $-0,45$ \\
\hline San Andrés y Providencia & & 1,07 & 1,20 & \\
\hline Santander & 0,9 & 1,37 & 2,29 & 1,39 \\
\hline Sucre & 0,63 & 0,50 & 0,58 & $-0,05$ \\
\hline Tolima & 0,73 & 0,82 & 0,91 & 0,18 \\
\hline Valle del Cauca & 1,17 & 1,26 & 1,24 & 0,07 \\
\hline
\end{tabular}

Fuente: Meisel (1999), DANE y cálculos propios.

Durante la segunda mitad del siglo XX se deterioró la evolución de los departamentos costeños, la cual fue muy dramática en el Atlántico que, de un PIB por habitante casi el $80 \%$ superior al promedio nacional en 1950, lo igualó en 2015. Lo mismo sucedió, en menor medida, en Magdalena y Sucre en ese período, que solo representan el $60 \%$ del promedio nacional. Los que tuvieron un desarrollo minero, como La Guajira, Cesar y Córdoba, registraron leves mejoras hacia 2000, que no lograron consolidar porque el PIB minero está dominado por las utilidades de las empresas que explotan carbón o níquel, las que solo recirculan en la región 
cuando hacen nuevas inversiones; el resto del tiempo ni siquiera se gastan en el país. Solo Bolívar, Cesar y Atlántico están cerca del promedio nacional; los demás son bastante pobres. El PIB de Bolívar es un 10\% superior al promedio nacional, el mejor desempeño de la Costa Caribe, gracias a la Refinería de Cartagena (Reficar) y a su ampliación, a que es un nicho de la industria química y de turismo de alta gama y a la gran dinámica del sector de la construcción. Algo similar empieza a suceder en Santa Marta, pero en menor medida. El Cesar desarrolló una agroindustria dinámica durante los últimos treinta años, con el mejor desempeño de la región, seguido de Sucre y Magdalena que partieron de una base de extrema pobreza.

A nivel nacional, las entidades territoriales más ricas en 2015 eran Meta, con 2,4 veces el promedio; Santander, con 2,3; Bogotá, con 1,9; Boyacá, con 1,4; Antioquia, con 1,3; y Valle del Cauca, con 1,2. El triángulo de oro de la protección ha perdido su lustre, aunque no del todo. Las más pobres son Chocó, con 0,5; Nariño y Norte de Santander, con 0,55; Caldas y Sucre, con 0,58; Córdoba, con 0,6; y La Guajira, con 0,63 (tabla 3).

Tabla 3. Evolución del PIB per cápita COP de 2015 y porcentaje

\begin{tabular}{cccc}
\hline Departamento & 1990 & 2015 & Crecimiento \\
\hline Atlántico & 7,8 & 13,3 & 71,5 \\
Bolívar & 8,2 & 14,6 & 77,4 \\
Cesar & 5,9 & 13,9 & 134,8 \\
Córdoba & 4,3 & 8,1 & 87,6 \\
La Guajira & 8,1 & 8,5 & 4,1 \\
Magdalena & 4,3 & 8,2 & 90,3 \\
Sucre & 3,9 & 7,7 & 98,3 \\
Colombia & & & 72,3 \\
Bogotá & & 50,7 \\
Antioquia & & 62,4 \\
Valle del Cauca & & 65,3 \\
\hline
\end{tabular}

Fuente: Piedrahíta, Pérez y Londoño (2017).

La evolución del PIB per cápita muestra algunas diferencias interesantes entre la región y el promedio nacional. Solo Atlántico y de lejos La Guajira muestran un crecimiento inferior al del PIB per cápita nacional. Cesar registra el mayor crecimiento, seguido de Sucre, Magdalena y Córdoba. Todos ellos, excepto La Guajira, superan el crecimiento de Bogotá y de Antioquia y Valle (tabla 4).

Con respecto a la pobreza monetaria, Atlántico es el único que muestra un resultado mejor que el promedio nacional; todos los demás siguen siendo más wpobres a pesar de que se observa un rápido progreso de los más rezagados. Persisten, entonces, índices de pobreza muy agudos que reflejan las relaciones ancestrales de desigualdad entre las élites, los campesinos y las grandes corrientes de desplazados que se refugian en los barrios marginales de sus ciudades. 
Tabla 4. Pobreza monetaria como \% de la población

\begin{tabular}{cccc}
\hline Departamento & 2005 & 2010 & 2015 \\
\hline Nacional & 45 & 40 & 28 \\
Atlántico & 49 & 48 & 26 \\
Bolívar & 52 & 57 & 39 \\
Cesar & 56 & 58 & 42 \\
Córdoba & 64 & 62 & 47 \\
La Guajira & 58 & 67 & 53 \\
Magdalena & 57 & 58 & 45 \\
Sucre & 64 & 66 & 45 \\
\hline
\end{tabular}

Fuente: Piedrahíta et al. (2017).

Detrás de las mejoras económicas de la Costa Caribe está el desarrollo de su industria y de la minería del carbón en el Cesar. Según los datos del DANE, entre 1997 y 2015 la industria regional registró un aumento importante de la producción bruta y del valor agregado, con tasas anuales promedio del $4,1 \%$ y el $2,8 \%$ respectivamente. Mientras que el primer indicador creció ligeramente más que el promedio nacional (4,0\%) el segundo creció menos (3,0\%).

Bolívar superó a Atlántico en 2017; el primero aportó el 6,7\% del valor agregado manufacturero nacional y el segundo, el 6,5\%. La Costa Caribe pasó de representar el 13,3\% del PIB manufacturero en 2000 al 16,5\% en 2016, a lo cual también aportaron Magdalena, Cesar y Sucre. La riqueza de Bogotá se basa en su industria diversificada, parte de la cual ha migrado a municipios circundantes como Cota, Chía, Tocancipá y Zipaquirá; su área de influencia incluye a los ricos municipios agroindustriales de la sabana cundiboyacense y es epicentro de las redes comerciales nacionales. El centralismo político ha favorecido en especial a Bogotá por el gasto de la nómina de todas las dependencias de los gobiernos nacional y departamental, y además porque es sede de las grandes empresas del país y de las multinacionales que invierten en Colombia. Aunque algunas grandes empresas de Antioquia, Atlántico y Valle del Cauca también se localizan en sus propias regiones. La base tributaria de la capital es, por tanto, bastante mayor que las de otros municipios; además, sus alcaldes han contado con mayor autonomía y han recurrido a un mayor recaudo de impuestos prediales y de industria y comercio, que ha servido para profundizar su desarrollo. La ventaja de Bogotá frente a las demás regiones era mayor en 1950, 2,4 veces más que el promedio nacional, y en 2015 es solo un 93\% mayor, debido en parte a que su población creció más que las de las otras ciudades y departamentos del país. Según Meisel (1999), Bogotá toma más ventaja cuando se construye un índice de ingreso neto que contabiliza traslados de utilidades y de impuestos entre sus periferias.

La influencia política de Antioquia, Cundinamarca, Bogotá y Valle del Cauca ha resultado en mejores dotaciones de obras públicas en infraestructuras, y en una mayor representación en el Congreso y en el Ejecutivo que la de la Costa Caribe. El Valle del Cauca se deterioró por la presencia del narcotráfico que, entre otras consecuencias nocivas de criminalidad, provocó una revaluación local del peso (Piedrahita et al., 2018). La apertura económica y el surgimiento de las exportaciones minero-energéticas en varias regiones nuevas del país coincidieron con 
el ocaso de la industrialización en el triángulo de oro, que terminó debilitando las regiones que predominaron durante el siglo XX.

\section{¿Por qué no creció más la Costa Caribe?}

Según Meisel, la Costa Caribe perdió el siglo XX porque el producto clave de exportación, el café, jalonó el mayor desarrollo de la región exportadora, que mediante sus encadenamientos contagió al resto de regiones. Meisel recurre a las teorías de Ennis, Hirschman y North para sustentar su hipótesis. Ennis aduce que el desarrollo de una región depende de su participación en la producción y la comercialización del bien exportado. Hirschman estableció que los encadenamientos hacia atrás y adelante dan cuenta del impacto regional. North diferencia entre el sector exportador dinámico y el sector residente que depende del primero. Señala, además, que una economía de plantación exportadora tiene menos eslabonamientos con los demás sectores que una economía basada en unidades familiares también exportadora (Meisel, 1999, pp. 70-73).

En la Costa Caribe hubo plantaciones de banano y grandes haciendas ganaderas, las primeras exportaban casi toda su producción, las segundan asumían la forma de una economía residente y producían para el mercado interno, ambas con pocos efectos multiplicadores sobre la economía de la región, mientras que la gran dinámica cafetera fue resultado de que el cultivo fue acogido por unidades familiares antioqueñas que también lo sembraron en sus zonas de colonización. De ahí en adelante los altos precios del café provocaron una revaluación relativa de la tasa de cambio, un desplazamiento de las exportaciones que no contenían renta (como el banano y otras en potencia) y un desarrollo más lento de la producción de bienes transables a causa de las importaciones que financiaba el producto estrella.

El arancel a las importaciones del país se elevó a niveles del 50\% durante la Gran Depresión para irse reduciendo hasta el 10\% hacia 1945. Según García-García (2008), la política comercial restrictiva adoptada durante la segunda república conservadora (1949-1957) elevó el arancel a un $20 \%$, introdujo medidas paraarancelarias cada vez mayores que incluían listas de prohibida importación, licencias y gravámenes especiales, y una tasa de cambio fija que no podía ser defendida. En 1967 se estableció una tasa de cambio flotante que ayudó a recuperar las exportaciones no tradicionales, pero una nueva bonanza, a mediados de la década de 1970, les restó impulsó. Hasta 1990 se reprimieron las importaciones, que se encarecieron por los gravámenes a los consumidores y a una tasa de cambio revaluada que frenó las exportaciones diferentes del café. Incluidas las exportaciones de ganado y de algodón de la Costa Caribe. Según García-García,

Un régimen de apertura comercial y un tipo de cambio de equilibrio habrían contribuido enormemente a elevar la productividad del sector ganadero y la del agropecuario en general. Semejante política hubiera elevado el precio de los bienes transables y dado lugar, en consecuencia, a mayor producción de cultivos y mayor demanda por tierras de cultivo. (García-García, 2008, pp. 184-185)

El contrafactual de García-García (2008) continuaba con una valorización de las tierras que habría inducido a los ganaderos a aumentar la productividad con mejores prácticas. En el pe- 
riodo 1991-2015, el PIB de Atlántico creció al 3,8\% anual, menos que el de Santander (4,7\%), pero más que el de Bogotá y el de Antioquia (que rondaron el 3,5\%). La apertura no fue tan amplia medida por el arancel, que se mantuvo alrededor del 12\% hasta 2014, pero sí al eliminar todas las trabas paraarancelarias, como las listas de prohibida importación o los requerimientos de licencias para importar casi todos los bienes, que se levantaron durante la Administración de Virgilio Barco (1986-1990). El arancel se redujo al 6\% desde 2014, el cual no es un nivel bajo comparado con los patrones internacionales. Lo cierto es que la apertura iniciada en la década de 1990 no condujo a la situación idealizada por García-García (2008), pues las exportaciones de la Costa Caribe no despegaron, la carga en las fincas ganaderas siguió siendo baja, así como la productividad, y la aftosa impidió exportar carne a los grandes mercados, mientras que la expansión de la frontera y el conflicto interno aumentaron la concentración de las tierras, desplazando a millones de campesinos, sin desarrollar apreciablemente el sector agropecuario.

En el caso del algodón, se adoptaron políticas sesgadas en favor del triángulo de oro, que incluían una protección a su industria textil que desestimuló las exportaciones en las que la Costa Caribe habría sacado mayor provecho. El favorecimiento de la industria conformó un monopsonio, llamado Diagonal, que impuso precios inferiores a los internacionales, al tiempo que se restringían las exportaciones de la fibra. Las políticas públicas oscilaban entre favorecer a textileros y graseros (que extraían aceite de la semilla de algodón) o a los algodoneros. Aunque se reprimieron las importaciones de la fibra, también se reprimieron sus exportaciones para garantizar el abastecimiento de la industria textil.

Para García-García (2008), la economía política de la protección benefició más a los industriales del triángulo de oro que a los de Barranquilla, que se vieron sometidos a la competencia del contrabando, que no llegaba de manera tan abierta al interior del país. La renta de los exportadores fue compartida por los industriales, al disponer de maquinaria y equipo importados sin aranceles y una tasa de cambio subvaluada, mientras que las rentas obtenidas por vender más caro en un mercado cautivo eran compartidas con los sindicatos de trabajadores que surgieron con la República liberal.

El crédito subsidiado estimuló las rentas de los productores, pero suscitó imprevisión, desincentivó la reducción de costos y llevó a que la tasa de interés señalara cuáles eran en verdad las actividades que podían pagarla y que no fuera la mano del Gobierno la que asignara el crédito. El cultivo de algodón se extendió en el Meta y la Costa Caribe hasta la década de 1970; después los precios internacionales cayeron y el algodón colombiano no pudo competir en el mercado global, como le sucedió a todos los productos de exportación del país durante el siglo XIX. Faltaron, como siempre, bienes públicos que redujeran los costos de transporte y de logística y no se trazó una política de investigación que adaptara variedades resistentes a las condiciones locales. La baja internacional de los precios, el manejo inadecuado de las tierras y las plagas se combinaron para liquidar la actividad. La bonanza algodonera no se utilizó para enfrentar una crisis con alternativas productivas. El gremio algodonero habría podido recaudar un impuesto temporal para financiar la investigación, la educación de sus trabajadores y el desarrollo de alternativas como la palmicultura y la ganadería tecnificada. En su balance, García-García (2008) estima que los productores algodoneros perdieron parte de la bonanza a favor de los industriales, que utilizaban materias primas a precios inferiores a los internacionales, sobre todo cuando estos eran altos. 
La argumentación de Meisel (1999, pp. 75 y 76) es más sutil, pues plantea que el producto estrella ocasionó la enfermedad holandesa en la década de 1930 al revaluar la tasa de cambio y desincentivar las exportaciones de banano y productos agropecuarios en general, lo que fue cierto hasta que se acabó el Pacto Cafetero en 1989 y las cotizaciones del grano descendieron (figura 1).

Figura 1. Índice tasa de cambio real

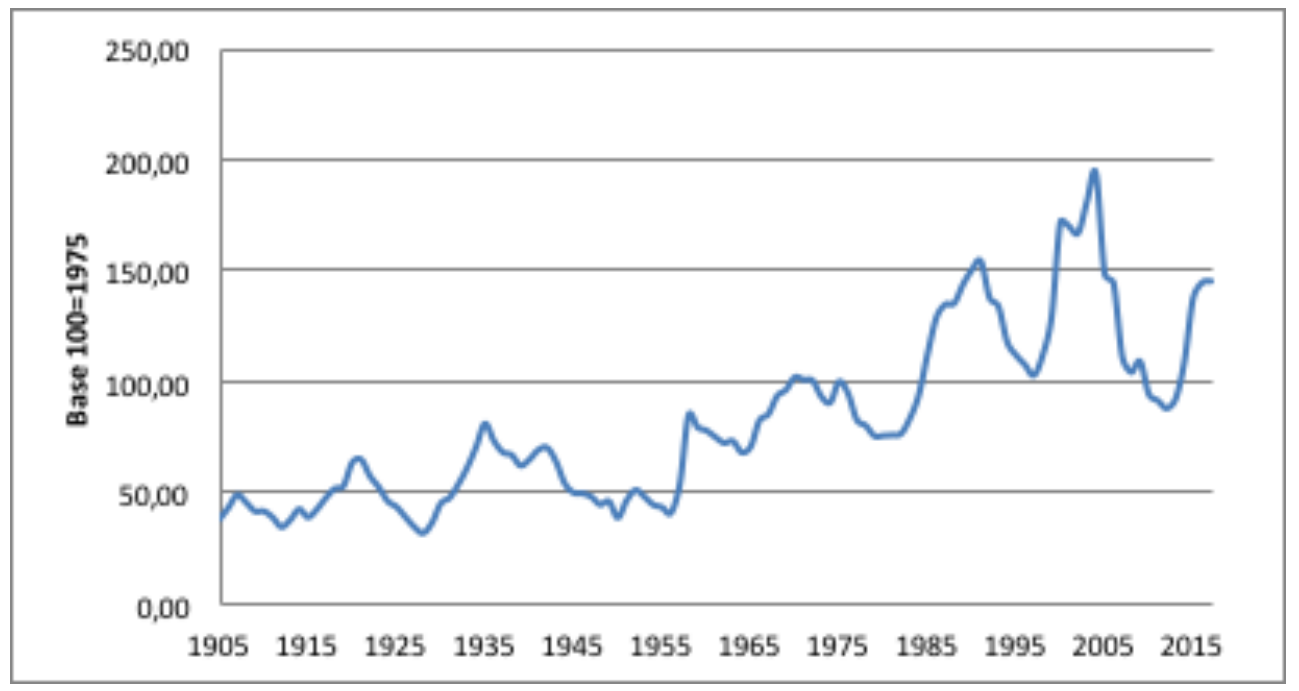

Fuente: Kalmanovitz y López (2019).

La gráfica de la tasa de cambio real muestra que hubo una revaluación sostenida del peso entre 1921 y 1927, una devaluación durante la Gran Depresión y una nueva fase de fuerte revaluación entre 1935 y 1955. De ahí en adelante la devaluación del peso fue significativa, con períodos revaluatorios en la década de 1990 y entre 2004 y 2014 que revivieron la enfermedad holandesa y contribuyeron a la desindustrialización de Bogotá, Cali, Medellín y Barranquilla, pero no de Cartagena. Por lo demás, el triángulo de oro generaba externalidades y menores costos de transporte que las ciudades de la Costa Caribe. La irregularidad de la navegación por el río Magdalena y el fracaso del Ferrocarril del Norte, junto a las dificultades de acceso al puerto de Barranquilla, aislaron la Costa Caribe de los impulsos provenientes del triángulo industrial del interior.

Así, la protección favoreció a las industrias del interior y perjudicó a los productores de materias primas, a los que les impidió exportar sin límites, sujetos a incentivos inconvenientes de tasa de cambio e inflación. Los industriales de la Costa Caribe enfrentaban una fuerte competencia del contrabando, menos intensa en el interior. Según García-García (2008), "los altos aranceles, [las] fuertes restricciones a las importaciones y un peso sobrevaluado" dificultaron la industrialización de la región Caribe. Pero la apertura de la década de 1990 parece haberle sido favorable, pues tendió a converger hacia el promedio nacional, aunque sin un progreso notable. La razón podría ser que las bonanzas minero-energéticas desataron procesos de desindustrialización que hicieron mella en la industria barranquillera, de la cual solo se salvaron las empresas exportadoras, como Industrias Cannon, Sempertex y Tecnoglass. 
La industrialización lograda hasta la década de 1970, tan dependiente de la protección, se debilitó a medida que una nueva enfermedad holandesa, más aguda y basada en las exportaciones mineras y petroleras desde la década de 1990 provocaba una fuerte revaluación de la moneda y el desplazamiento de producción nacional por importaciones. Esta vez la política macroeconómica contribuyó a ese resultado, pues no gravó las rentas de exportación que se habrían podido ahorrar fuera del país, reduciendo el impacto sobre la tasa de cambio; en cambio, los gobiernos de turno no solo no ahorraron sino que aprovecharon la bonanza para endeudarse interna y externamente, así agravaron la revaluación del peso y perjudicaron la producción de bienes transables (Kalmanovitz, 2018).

La desindustrialización, muy fuerte en Barranquilla, Antioquia y Cali-Yumbo, también afectó a Bogotá, y se agravó por el traslado de empresas a zonas francas y municipios vecinos, donde los precios de la tierra eran más bajos, que ofrecían exenciones de impuestos locales a las empresas que se trasladaran. De ese proceso se salvó Cartagena, por la construcción de la refinería en Mamonal por la Empresa Colombiana de Petróleos (Ecopetrol) y su reciente modernización y ampliación. Esta fue la única ciudad que se industrializó entre 1990 y 2017, mientras que las demás regiones industriales se subdesarrollaban.

\section{Factores propios que no ayudaron}

Ni García-García (2008) ni Meisel (1999) consideran las relaciones entre terratenientes y campesinos en la Costa Caribe, caracterizadas por una gran desigualdad en el acceso a la propiedad de la tierra, a la riqueza y a la educación. El primero de esos autores sostiene que ganadería y la agricultura solo necesitaban los incentivos del mercado global, que se habrían generado con políticas de liberación comercial; algo que puede ser parcialmente cierto pero omite que la estructura social de la región fue un obstáculo para la formación de un mercado interno dinámico y dificultó la acumulación de capital humano. También le dio alas al sistema clientelista de mercado y a la corrupción, que inciden en la debilidad estatal y en la escasez de bienes públicos que lubriquen el desarrollo económico.

En efecto, la aguda concentración de las tierras y el atraso agrícola no dieron lugar a un campesinado próspero y educado que constituyera demanda para la industria pionera que se localizó en Barranquilla y Cartagena, a diferencia del campesinado cafetero de occidente, que obtuvo altos índices de alfabetización y se constituyó en una fuente de demanda dinámica para la industria del triángulo del interior, algo que Meisel (1999) sí reconoce al diferenciar los impactos de economías de plantación o de enclave y economías basadas en granjas familiares. Antes del auge cafetero, los mineros independientes de oro antioqueño habían logrado una acumulación de capital relativamente democrática y al surgimiento de la arriería que dio lugar a un capital comercial ampliamente diseminado en el territorio.

Cabe preguntarse si la concentración de la tierra sigue siendo un factor que impida la modernización agrícola. Lo que ha estado sucediendo en las planicies de Cesar, Sucre y La Guajira es el desarrollo de plantaciones de palma africana con su derivado industrial de aceite, lo cual puede explicar parte de su desarrollo económico reciente.

La concentración de la propiedad de la tierra en la Costa Caribe parece ser menor que a nivel nacional según los datos del censo nacional agropecuario de 2014. El Gini de concentración 
de la tierra a 0,88 en 2014 llegó, uno de los más altos del mundo, frente al 0,72 en 1970. La concentración medida por las propiedades mayores de 1.000 hectáreas es mucho mayor a nivel nacional que en el Caribe, salvo en La Guajira (donde es del 57,1\% frente al 51\% nacional). El segundo de mayor concentración es Córdoba con el 48,5\%, seguido de Atlántico con el $43,3 \%$ y de Cesar con el 39,6\%. En los demás es inferior al 40\%. Se puede colegir entonces que la colonización de frontera, que añadió 13 millones de hectáreas al universo agropecuario (sin contar territorios étnicos) que existía en 1970, se tomó enormes espacios que empeoraron la distribución de la tierra.

El conflicto interno desplazó a siete millones de personas y concentró las unidades de tamaño medio, según lbáñez (2008). Así aumentó notablemente la concentración a nivel nacional, pese a la apertura de nuevos territorios, aunque en menor grado en las áreas de la Costa Caribe situadas dentro de la frontera agrícola, salvo en La Guajira y en Córdoba donde hubo una alta concentración. En comparación con el promedio nacional, hay menos propiedades pequeñas en la Costa Caribe, pero abundan las de 10 a 50 hectáreas (tabla 5).

Tabla 5. Tenencia de la tierra en los departamentos de la Costa Caribe

\begin{tabular}{ccccccccc}
\hline $\begin{array}{c}\text { Total nacional } \\
\text { (hectáreas) }\end{array}$ & $\begin{array}{c}\text { Nacional } \\
(\%)\end{array}$ & $\begin{array}{c}\text { Atlántico } \\
(\%)\end{array}$ & $\begin{array}{c}\text { Bolívar } \\
(\%)\end{array}$ & $\begin{array}{c}\text { Cesar } \\
(\%)\end{array}$ & $\begin{array}{c}\text { Córdoba } \\
(\%)\end{array}$ & $\begin{array}{c}\text { La Guajira } \\
(\%)\end{array}$ & $\begin{array}{c}\text { Magdalena } \\
(\%)\end{array}$ & $\begin{array}{c}\text { Sucre } \\
(\%)\end{array}$ \\
\hline Menos de 5 & 4,3 & 5,7 & 2,6 & 0,9 & 3,1 & 1,7 & 1,9 & 3,5 \\
5 a 10 & 3,4 & 6,0 & 4,5 & 1,6 & 2,9 & 2,1 & 2,8 & 4,8 \\
10 a 50 & 12,8 & 18,6 & 22,0 & 15,7 & 12,5 & 11,1 & 21,5 & 23,0 \\
50 a 100 & 7,1 & 8,0 & 10,3 & 11,7 & 7,7 & 6,6 & 13,7 & 11,6 \\
100 a 500 & 15,3 & 14,2 & 18,6 & 27,7 & 20,9 & 13,7 & 27,5 & 25,0 \\
500 a 1.000 & 6,1 & 4,2 & 5,4 & 7,8 & 8,4 & 6,2 & 7,3 & 7,7 \\
Más de 1.000 & 51,1 & 43,3 & 36,6 & 34,6 & 44,5 & 58,5 & 25,3 & 24,3 \\
\hline
\end{tabular}

Fuente: DANE y censo nacional agropecuario de 2014.

La opción que le quedaba a la Costa Caribe, dadas las limitaciones impuestas por su estructura social, era el mercado mundial. La política de protección la llevó en la dirección contraria: una dependencia excesiva del mercado del triángulo de oro, cuyo acceso estaba restringido por los altos costos de transporte desde la región Caribe. Siempre hubo incentivos para exportar, sobre todo a los países y las islas del Caribe, con mercados también pequeños. En otras regiones del país también se atrofió el desarrollo económico debido a las políticas centralistas, en especial en el Pacífico chocoano y nariñense, que incluye a Buenaventura, un puerto de enclave, pero también en la región oriental, que depende de la dinámica de la economía venezolana en franca contracción, y en zonas de expansión de la frontera agrícola, desde el Caquetá y Putumayo a los Llanos Orientales, que se vieron envueltas en el conflicto interno posterior y experimentaron una gran concentración de las nuevas tierras. 


\section{Construcción de Estado nacional y local}

El sistema político colombiano se basó en el clientelismo organizado por los dos grandes partidos históricos, el Liberal y el Conservador, el cual determinó la organización centralista, autoritaria y confesional del Estado moderno que restringió los derechos electorales de la mayoría de la población de la época. El esquema constitucional fue limitado por unos acuerdos de tolerancia con la oposición después de la guerra de los Mil Días y por un talante desarrollista de 1905 en adelante. El Estado era mínimo, con un recaudo del Gobierno central inferior al $5 \%$ del PIB hasta la década de 1950, que creció a la par con la riqueza nacional, y las oligarquías regionales y locales designaban a los funcionarios del Ejecutivo. Los problemas de orden público se enfrentaban recurriendo a grupos armados por terratenientes; el ejército y la policía eran débiles y no eran cuerpos profesionales.

La capacidad para proporcionar bienes públicos fue bastante limitada, sin cobertura universal de la educación y de la salud hasta la llegada del siglo XXI. Las amenazas a la seguridad nacional generadas por el narcotráfico y la insurgencia desde la década de 1980 hicieron palpable la inexistencia del monopolio de los medios de violencia, un rasgo fundamental del Estado moderno. La reacción de las élites fue aumentar la tributación y las contribuciones para fortalecer la capacidad militar y construir una red de atención a las necesidades sociales. El recaudo del Gobierno central llegó entonces a casi un 15\% del PIB y las contribuciones a la seguridad social a otro 5\% del PIB. Se fortaleció el sistema de justicia, pero siguió clientelizado y no garantizaba la resolución de conflictos entre ciudadanos ni protegía efectivamente sus derechos de propiedad. El déficit de bienes públicos -y su mala calidad cuando existían-, la inseguridad, la corrupción endémica y las deficientes políticas macroeconómicas han frenado, de una u otra manera, el desarrollo económico del país.

El mayor tamaño del Estado colombiano y las transferencias a municipios y departamentos aumentaron las oportunidades para que los políticos y los funcionarios se apropiaran una parte de estos recursos. El clientelismo se puede definir así:

Como un mecanismo no institucional de lealtades asimétricas mediante el cual se intercambian bienes y servicios por apoyo electoral, práctica legendaria en la historia política del Estado colombiano. El tipo de clientelismo que predomina actualmente es el clientelismo de mercado, que tiene un carácter predominantemente local, tiene a los políticos como protagonistas y se vale de la existencia de nuevas reformas institucionales tales como la descentralización, la elección popular y los mecanismos de participación para conseguir recursos, muchas veces de tipo ilegal. Su función consiste en distribuir recursos en las localidades, bajo la intermediación de los caciques políticos ligados, a su turno, a los miembros del Congreso Nacional. (Newman \& Ángel, 2017, pp. 20-21)

La gran oleada de corrupción en el gasto público en obras y servicios subcontratados ha sido facilitada por el financiamiento privado de las campañas electorales, mediante el cual los contratistas logran que los políticos elegidos les devuelvan los favores recibidos por medio de la contratación preferencial, sin competencia real alguna.

La corrupción se profundizó a medida que el largo conflicto interno congeló la política e impidió que surgieran nuevas fuerzas y partidos que hicieran oposición al Gobierno de turno y vigilaran sus actividades. La separación de poderes se volvió precaria y la independencia del 
poder judicial se debilitó. La fortaleza de la Fiscalía ha mostrado que sirve además para albergar un enorme grado de corrupción. Y, por encima de todo, el narcotráfico, con sus abundantes recursos desde la década de 1980, deterioró la integridad del poder ejecutivo, de la fuerza pública y socavó aún más el sistema de justicia.

El narcotráfico, que se inició con el cultivo de marihuana en La Guajira y en la Sierra Nevada de Santa Marta en la década de 1970, creó excedentes ilegales mucho mayores de los que proveían del contrabando tradicional que burlaba las políticas proteccionistas del Gobierno central y corrompía a sus agentes aduaneros. Colombia se convirtió en nicho de actividades criminales debido a la impunidad y a la falta de controles sociales que las rechazaran con firmeza (Thoumi, 1999). En efecto,

El narcotráfico es una economía ilegal, que en tanto genera riesgos, requiere de ciertas inmunidades para poder subsistir. Por esa razón, los empresarios de la droga deben desarrollar mecanismos de protección eficaces para el desarrollo de sus actividades, como lo son los grandes recursos en capital, el secreto y la violencia. (Newman \& Ángel, 2017, p. 22)

Según Newman y Ángel (2017), las formas más frecuentes de corrupción en el país son el soborno de funcionarios, la apropiación de bienes públicos y de bienes privados por funcionarios, el tráfico de influencias, el nepotismo y la extorsión. La amplitud de la corrupción está asociada a

la debilidad institucional del Estado. Mauricio García Villegas (2010) ha caracterizado a Colombia como un Estado débil, y en otras ocasiones lo ha descrito como un Estado premoderno. En últimas, se trata de un Estado dispar, ubicado en un punto intermedio entre el Estado ausente y el Estado constitucional, y que por esa misma razón, no ha logrado llegar a la modernidad. Y no lo ha hecho porque se encuentra compuesto de instituciones débiles que no logran imponer el imperio de la ley y que, por consiguiente, deben estar en constante negociación con actores políticos. En consecuencia, la incapacidad del Estado para ejercer el imperium ha desembocado en la primacía de redes locales y regionales de poder, que han impedido que el Estado logre diferenciarse de los intereses privados de los sectores dominantes. (Newman \& Ángel, 2017, p. 24)

Además, "Mauricio García y Javier Eduardo Revelo (2010) sugieren que en una buena porción de la periferia nacional el clientelismo de mercado ya ha pasado a ser clientelismo armado y mafioso, que surge de la unión entre las prácticas clientelistas y las grandes organizaciones criminales" (Newman \& Ángel, 2017, p. 21).

La construcción de Estado local y regional fue todavía más limitada que la del Estado central. La Regeneración expropió a los otrora estados soberanos y municipios de los impuestos que alcanzaron a recaudar y usurpó sus responsabilidades de gasto, que se tornó insuficiente e ineficaz con las decisiones tomadas desde la paramuna capital sin mayor conocimiento y limitadas consultas a las élites locales de su misma inclinación partidista. Solo se devolvían algunos de los impuestos locales recaudados, pero con especificaciones precisas de gasto. Se desarrolló así una mentalidad pedigüeña en las regiones así como la visión fatalista de que todos sus problemas obedecen al centralismo, sin asumir su destino y sus propias decisiones. Si el déficit del Estado central fue un freno importante para el desarrollo nacional, el faltante 
municipal, y aún mayor el regional, paralizó las fuerzas productivas de los departamentos y ciudades más pobres del país.

La destrucción de los estados soberanos por la Regeneración ocasionó la atomización administrativa de las regiones y la atrofia presupuestaria de los departamentos. La vida municipal empezó a revivir durante el siglo XX, con ayuda del impuesto predial y eventualmente del de industria y comercio, que dieron sustento económico a las grandes ciudades pero no a los municipios pequeños. La corrupción es mayor en las regiones atrasadas, donde la pobreza hace posible que los caciques compren votos, se hagan elegir y capturen los presupuestos. En las ciudades eso es más difícil, pero ocurre si las élites económicas legales no se preocupan por influir en la política y procuran limpiarla de la corrupción y el desvío de recursos públicos.

No obstante, las ciudades más prósperas -Bogotá, Medellín, Cali y Barranquilla- pudieron diseñar y ejecutar planes de desarrollo, y establecer empresas de servicios públicos a partir de 1910. Barranquilla, Cartagena y Valledupar tuvieron buenas administraciones municipales, bastante privatizadas por cierto, en las décadas de 1940 y 1950, que se acabaron con los intentos de nacionalizar la prestación de los servicios públicos en la década de 1960. Se deterioraron en todo el país, pero fueron canibalizados en la Costa Caribe. Barranquilla y Santa Marta hasta hace unas décadas, Riohacha y Cartagena hasta el presente, han tenido malas administraciones públicas. Valledupar y Montería obtuvieron buenos resultados en sus planes urbanísticos y de servicios durante las últimas tres o cuatro décadas.

Hacia 1990 imperaban la corrupción y la desidia en las ciudades de la Costa Caribe. En Barranquilla había racionamiento de energía, agua y teléfono debido al manejo clientelista y corrupto de sus empresas públicas, que propició la salida de industrias y alejó las nuevas inversiones, e inició así su proceso de desindustrialización. Las privatizaciones de la década de 1990 enfrentaron esa situación, pero no proporcionaron servicios públicos a precios razonables: puesto que las negociaciones fueron deficientes y no se mantuvo el control de parte de los activos, la prestación de los servicios fue limitada y de mala calidad. En cambio, Bogotá no privatizó su acueducto y capitalizó parcialmente su empresa de energía con aportes extranjeros, y Medellín nunca tuvo que privatizar su eficiente Empresas Públicas de Medellín (EPM). En Cali también hubo una involución en la prestación de servicios públicos.

En varias ciudades donde los grupos paramilitares controlaban la política, se les concesionó el recaudo tributario y lo mantuvieron bajo, pero se apropiaron de una parte sustancial. Esto fue notorio en Urabá y en el sur de Antioquia, en el Magdalena Medio y en los Llanos Orientales. En la Costa Caribe se destacaron Barranquilla, Santa Marta y Riohacha. En muchos municipios, las transferencias de la nación también se desviaban hacia los grupos armados que ejercían una hegemonía política de facto. El conflicto interno fue especialmente intenso en La Guajira y Cesar, Bolívar y Córdoba, donde provocó el éxodo masivo de campesinos que hoy ocupan barrios tuguriales de las grandes ciudades, en especial de Cartagena, Barranquilla, Santa Marta y Montería. Las élites económicas parecían haber descuidado la administración de sus ciudades y entregársela a camarillas clientelistas que devoraban los recursos públicos y no impulsaban la inversión pública.

Con todo, la elección popular de alcaldes desde 1986 ha contribuido a despertar las energías de todas las ciudades del país, en diferentes momentos. En algunas, los movimientos cívicos apo- 
yados por las élites empresariales le dieron un vuelco a la tendencia y recuperaron las finanzas públicas. La necesidad de atender las aspiraciones de los ciudadanos ha contribuido a tecnificar las secretarías de Hacienda y a aumentar el recaudo tributario para financiar obras de desarrollo urbano que terminan siendo reconocidas electoralmente.

La descentralización iniciada por la Constitución de 1991 contribuyó a que los municipios más pobres contaran con recursos mínimos e incentivó el aumento de los recursos propios. Según Pérez-Valbuena y Bonet-Morón (2018), existen patrones regionales. Las ciudades de las regiones Pacífica y Caribe parecen mostrar fragilidad estructural de largo plazo. En las regiones del interior, Oriental y Central en particular, los desafíos tienen mayor relación con los flujos de caja y la sostenibilidad de corto plazo.

Sin embargo, no parce haber fallas protuberantes en los gobiernos de las ciudades de la Costa Caribe en comparación con las demás. Para tomar uno de los indicadores principales, la capacidad para recaudar impuestos por habitante estimada por Pérez-Valbuena y Bonet-Morón (2018), en Barranquilla solo es menor que la de Bogotá, y mayor que la de Medellín y Cali. Incluso Cartagena, que ha tenido graves problemas de corrupción y una alta rotación de alcaldes, no está lejos de Medellín y supera a Cali. Valledupar recauda menos, pero aumentó el recaudo un 140\% entre 2011 y 2017. Montería es bastante pobre, pero amplió el recaudo por habitante en un 64\% entre esos mismos años, Santa Marta en un 73\% y Riohacha en un 76\%. Sincelejo, situada en uno de los departamentos más pobres del país, tiene una buena capacidad tributaria. Riohacha es la más pobre y su corrupción endémica puede explicar parte de ese resultado. En general, todas han despertado en el siglo XXI, y han descubierto su buena capacidad propia para movilizar recursos sin explotar y ejecutar obras públicas importantes que financien su progreso, sin depender tanto del Gobierno central.

Una de las conclusiones del estudio citado es la siguiente:

Las regiones de la periferia [...] tienen una mayor dependencia de las transferencias, una mayor debilidad de los recursos propios y una baja capacidad de ahorro. Las implicaciones de estos resultados son claras. En primer lugar, un alto porcentaje de las inversiones que se realizan en estas regiones rezagadas se lleva a cabo con transferencias, tanto en los departamentos como en los municipios. Esto lleva a una segunda implicación, y es la menor discrecionalidad en el uso de los recursos, ya que gran parte de estos tienen una destinación específica, lo que limita el margen de maniobra a las entidades territoriales para realizar las inversiones requeridas en el contexto de la necesidad de cada grupo poblacional en particular. (Pérez-Valbuena \& Bonet-Morón, 2018)

La manera de repartir las regalías a municipios y departamentos, que por mucho tiempo fueron concentradas y dilapidadas por los municipios con abundantes recursos naturales, es ahora más razonable, conforme a medidas de pobreza y de necesidades, y mayor disciplina en el gasto; aunque aún están lejos invertirse en forma racional.

La falta de desarrollo de la mayoría de los municipios del país se debe a que nunca se ha evaluado adecuadamente el valor de la propiedad agraria que los circunda, con un catastro técnicamente elaborado que se mantenga al día. Superando esa carencia se podrían recaudar impuestos prediales justos y suficientes para financiar las necesidades relacionadas con educación, salud y bienes públicos, así como acueductos y vías terciarias. 


\section{Algunas conclusiones}

A veinte años del pionero estudio de Meisel sobre la reversión del desarrollo de la Costa Caribe en el siglo XX, se puede constatar que eran ciertas muchas de sus apreciaciones y explicaciones de ese resultado. Las políticas de protección y los beneficios de la economía cafetera fueron capturados por el triángulo de oro en detrimento de la Costa Caribe; la enfermedad holandesa y la exclusión política empeoraron su situación.

Desde entonces las condiciones han cambiado para bien de la región: a medida que el producto estrella se fue debilitando en los mercados internacionales, las regiones antes beneficiadas sufrían una fuerte involución económica y surgían nuevos polos de desarrollo que descontaban distancia frente a los más avanzados.

El modelo proteccionista se abandonó en favor de la apertura comercial y de capitales que quizá benefició más a la región caribeña que a las demás. Las ciudades cercanas al mar se han beneficiado de los mayores flujos de comercio y de turismo, y se han convertido en polos de desarrollo industrial, con empresas que compiten en el mercado global. En otras regiones con vocación globalizante como Cali, y las medidas que tomaron los antioqueños para devolver la competitividad a las empresas que sobrevivieron al cambio de orientación, ha reaparecido una nueva industrialización, más delgada, combinada con servicios integrales.

El nuevo producto estrella es el petróleo que, a diferencia del café, es explotado en una economía de enclave con pocos eslabonamientos hacia atrás y hacia delante, que han beneficiado a Santander y a Cartagena. Hay que reconocer el hecho de que estar dominado por una empresa estatal produce unos resultados más expansivos para el resto de la sociedad en la forma de dividendos para la nación con los que financia bienes públicos que los que resultarían de unas rentas mineras en manos de empresas privadas y extranjeras a las que se les entregan exenciones de impuestos considerables. No obstante, esto no es necesario: una política tributaria más progresiva podría ayudar a financiar los bienes públicos que tanto requiere el país y desarrollar las regiones donde se localizan, pero esto depende de la política local, como lo indica la explotación de carbón en La Guajira, que poco ha contribuido a su desarrollo, aunque al parecer la extracción de carbón en El Cesar ha generado un mayor desarrollo en la región.

El petróleo crea problemas similares a los del café, en particular, el de la enfermedad holandesa, que se debe enfrentar con políticas macroeconómicas que neutralicen sus efectos más nocivos sobre la tasa de cambio y los sectores transables, y proporcionado bienes públicos que mejoren la productividad y hagan más competitiva la producción. Es apenas justo que los sectores que generan rentas por sus recursos naturales, que en derecho pertenecen al Estado y a todos los ciudadanos, las compartan para ahorrarlas o invertirlas en el bienestar de la sociedad, algo que los gobiernos del siglo XXI no quisieron aprovechar al ofrecer enormes exenciones tributarias.

La necesidad de un catastro de tierras rurales es apremiante y podría tener un efecto similar al que tuvo la modernización de los catastros urbanos: aumentar la tributación de que hoy disponen las ciudades que han logrado un mayor desarrollo económico.

La descentralización ha producido efectos benéficos sobre las administraciones locales, en especial donde existía un potencial tributario considerable que comenzó a ser explorado y explotado por muchas ciudades del país, en especial, por las del Caribe. Las transferencias 
también han ayudado, pero es la voluntad política propia de los ciudadanos la que puede conducir al desarrollo de sus terruños. El clientelismo y la corrupción que trae consigo se mantienen en muchas ciudades y, sobre todo, en los municipios de la Costa Caribe, y hay que tomar medidas para reducirlos. El surgimiento de movimientos cívicos ha ayudado a limpiar la política y a lograr que a nivel local se recurra a una tecnocracia que administre en forma adecuada las ciudades, los municipios y, por qué no, los departamentos. Los regímenes tributarios locales podrían ser más democráticos y captar más recursos para enfrentar los desafíos municipales, y a los departamentos se les debe proporcionar recursos fiscales mayores que los que aportan los impuestos a los vicios. La falta de un nivel departamental de gobierno bien financiado y representativo es uno de los grandes vacíos del sistema político colombiano y se debe superar para crear Estado desde abajo, desde los municipios, en coordinación con los departamentos y bajo el impulso del Gobierno central.

\section{Referencias}

Aguilera Díaz, M., Reina Aranza, Y., Orozco Gallo, A., Yabrudy Vega, J., \& Barcos Robles, R. (2018). Evolución socioeconómica de la región Caribe colombiana entre 1997 y 2017 . Documentos de Trabajo sobre Economía Regional y Urbana, 258. doi: https://doi.org/10.32468/dtseru.258

Cepeda Emiliani, L., \& Meisel, A. (2014). ¿Habrá una segunda oportunidad sobre la tierra? Instituciones coloniales y disparidades económicas regionales en Colombia. Revista de Economía Institucional, 16(31), 287-310. doi:https://doi.org/10.32468/dtseru.183

Fals Borda, O. (1984). Historia doble de la Costa. Volumen III: Resistencia en el San Jorge. Bogotá: Carlos Valencia.

García-García, J. (2008). Ensayos sobre comercio exterior y desarrollo económico. Cartagena: Banco de la República.

García Villegas, M., \& Revelo Rebolledo, J. E. (2010). Estado alterado: clientelismo, mafias y debilidad institucional en Colombia. Bogotá: Dejusticia.

Ibáñez Londoño, A. M. (2008). El desplazamiento forzoso en Colombia: un camino sin retorno hacia la pobreza. Bogotá: Universidad de los Andes.

Kalmanovitz, S. (ed.) (2015). Breve historia económica de Colombia. Bogotá: Universidad de Bogotá Jorge Tadeo Lozano.

Kalmanovitz, S., \& López Rivera, E. (eds.) (2019). Las cuentas del federalismo colombiano. Bogotá: Universidad Externado de Colombia.

Maddison, A. (2018). Maddison Project Data Base. Groningen, Holanda.

Meisel, A. (1999). ¿Por qué perdió la Costa Caribe el siglo XX? En A. Meisel (ed.), El rezago de la Costa Caribe colombiana. Cartagena: Banco de la República. Recuperado de http://www. banrep.gov.co/es/por-que-perdio-costa-caribe-siglo-xx

Newman Pont, V., \& Ángel Arango, M. (2017). Sobre la corrupción en Colombia: marco conceptual, diagnóstico y propuestas de política. Bogotá: Fedesarrollo. 
Pérez-Valbuena, G. J., \& Bonet-Morón, J. (2018). Municipal fiscal health in colombian main cities. Documentos de Trabajo de Economía Urbana y Regional, 274. doi: https://doi.org/10.32468/ dtseru. 274

Piedrahíta, E., Pérez, C., \& Londoño, H. (2017). Mientras llegaba el futuro: 25 años de apertura económica en el Valle del Cauca. Cali: Cámara de Comercio de Cali.

Thoumi, F. (1999). La relación entre corrupción y narcotráfico: un análisis general y algunas referencias a Colombia. Revista de Economía del Rosario, 2(1), 11-33. 